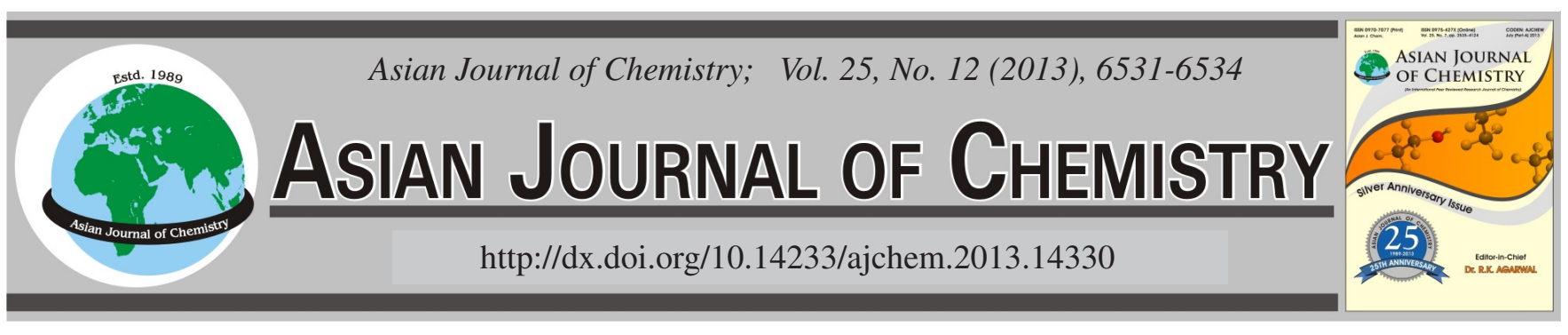

\title{
Analysis of Phenol in Cigarette Filter Tar Using QuEChERS Sample Preparation and High-Performance Liquid Chromatography/UV Detection System
}

\author{
A. Demirci* and B. Morkan
}

Department of Chemistry, Kirikkale University, 71450 Kirikkale, Turkey

*Corresponding author: Fax: +90 318 3572461; Tel: +90 505 3891086; E-mail: aydem55@yahoo.com.tr; aydemirci55@gmail.com

(Received: 19 July 2012;

Accepted: 20 May 2013)

AJC-13515

QuEChERS sample preparation was used for determination of phenol in cigarette filter tar. The method involved extraction with acetonitrile
followed by solid-phase extraction cleanup with XAD-4 sorbent and the analyse was carried out with a HPLC-UV equipment. The
method was validated using cigarette filter tar spiked at $30-125 \mu \mathrm{g}$ cigarette ${ }^{-1}$ and the recovery by the method varied from $83 \%$ to $120 \%$
with RSD $<15 \%$. The method showed good linearity $\left(\mathrm{r}^{2}=0.9989\right)$ and the LOD was $2.17 \mu \mathrm{g}^{-1}$ cigarette ${ }^{-1}$. The amount of phenol found in
the filter tar of the three brands of cigarettes were $13.02,10.23$ and $6.08 \mu \mathrm{g}$ cigarette ${ }^{-1}$, respectively.
Key Words: QuEChERS, Phenol, Cigarette, XAD-4, HPLC-UV.

\section{INTRODUCTION}

Phenol analysis in environmental samples draws great attention because of its widespread use in industry and high toxicological impact. They are widely used as preservative agents, pesticides, anticipates and disinfectants and in a variety of industrial applications ${ }^{1}$. For instance phenolic compounds are responsible for colour and contribute to the bitter flavour of wines ${ }^{2}$. Phenols together with several oxygen-containing compounds, such as carboxylic acids, alcohols, aldehydes, ethers make oils relatively reactive ${ }^{3}$. Some phenols are considered toxic ${ }^{4}$. They are also formed from heat treatment of biomass $^{5}$ and tobacco ${ }^{6}$.

It is well known that phenols are present in cigarette smoke and contribute to cigarette sensory properties ${ }^{7}$. Some tobacco companies add ingredients to tobacco products either to impart a specific taste, flavour or aroma to the product, or for a specific technological purpose such as increasing the moisture capacity of the tobacco. These ingredients volatile or non-volatile together with tobacco are the source of more than 4800 compounds found in smoke. For instance cellulose, chlorogenic acid, lignin is the sources of phenol, polycyclic aromatic hydrocarbons. There appear numerous articles and reviews describe phenol analysis ${ }^{8-10}$. It is interesting to note that the products from the combustion tobacco ingredients (volatile or non-volatile) were investigated (more correctly soaked) in smoke. For instance a method was given by British American tobacco group research and development for the determination of phenols in mainstream cigarette smoke ${ }^{11}$. There is almost no publication on the presence or the determination of phenolic compounds or Hoffmann analytes in tar. So to say tar is ignored. However, the presence of benz(a)pyrene and other polycyclic aromatic hydrocarbons in tar was shown in literature $^{12,13}$. Harmful effects of cigarette tar together with smoke are inevitable because cigarette butt is in touch with lips, tong and teeth. Tar leakage into stomach is also possible. Therefore the tar constituents must be determined.

Analytical techniques used in determination of phenols in samples such as water ${ }^{14}$, plants $^{15}$, pharmaceuticals ${ }^{16}$, are mainly high performance liquid chromatography and gas chromatography.

The high performance liquid chromatography systems in combination of ultraviolet detection ${ }^{17,18}$ fluorescence detection $^{2,19}$ or mass spectroscopy ${ }^{20,21}$ are applied while GC systems are used in combination of flame ionization detection ${ }^{22,23}$ or $\mathrm{MS}^{21,23,24}$. Apart from liquid and gas chromatographic techniques, gel permeation ${ }^{3}$ and micellar electrokinetic chromatography $^{25}$ are reported. However, none of these systems can achieve quantification limits required for the determination of phenols in various samples, making a preconcentration step (usually together with clean-up) necessary in the analytical scheme. The necessary preconcentration of phenol and its derivatives from liquid samples is commonly based on liquid-liquid extraction by a suitable solvent such as tricloromethane, diethyl ether, benzene, $n$-hexane or solid-phase extraction ${ }^{20,22,26-32}$.

The aim of this study is to develop, a fast, simple and low cost liquid chromatographic method to determine phenol in cigarette filter tar. The method was mainly based on successive 
solid-phase extraction and liquid-solid extraction and enrichment of phenol from cigarette filter tar and its quantification using high pressure liquid chromatography/UV detection system. This study will also contribute to quantify the combustion (pyrolysis) products ${ }^{33-35}$, (especially the phenolic compounds) found in smoke.

\section{EXPERIMENTAL}

Methanol, acetonitrile, (both high performance liquid chromatography grade), acetone, acetic acid and phenol (all analytical grade) were all purchased from Merck (Darmstadt, Germany) and deionized water was obtained using a Millipore ELIX 3 (USA) water purification system. Amberlite XAD-4 (mesh size $20-60 \mathrm{~mm}$, surface area $725 \mathrm{~m}^{2} / \mathrm{g}$, porosity $40 \AA$ ) was purchased from Sigma (USA). All solvents were filtered using filter system (Sartorius, AG, Germany) over $0.45 \mu \mathrm{m}$ pore size nylon membrane (Millipore, Germany).

The $\mathrm{pH}$ meter was obtained from Mettler Toledo (MP 220, USA). A magnetic stirrer (MS-H-Pro Magnetic Stirrer, Dragon Lab., USA) with a magnetic bar (10 $\mathrm{mm}$ length and $3 \mathrm{~mm}$ diameter, Supelco, USA) was used for mixing the model and real samples. Sample vials with PTFE-silicone septa $(15 \mathrm{~mL})$ were obtained from Supelco (Bellefonte, PA, USA). Three brands of cigarettes were purchased from a local market.

Instrumentation and chromatographic conditions: The high-performance liquid chromatography system used was obtained from Shimadzu (Japan) and was equipped with a UV spectrometer (Shimadzu, Japan).

The high performance liquid chromatography mobile phase was a mixture of water and methanol (70/30, $1 \%$ acetic acid) and was pumped at a flow rate of $1.0 \mathrm{~mL} \mathrm{~min}{ }^{-1}$. A $\mathrm{C}_{18}$ column $(4.6 \times 150 \mathrm{~mm}, 5 \mu \mathrm{m}$, Supelco, USA) was used as the analytical column; the detector was a UV spectrometer operating at $280 \mathrm{~nm}$. A $10-\mu \mathrm{L}$ high performance liquid chromatography injector (SGE LC, 22 gauge, Supelco, USA) was used to inject the solutions into the high performance liquid chromatography. The phenol elution time was $4 \mathrm{~min}$. For quantification peak areas were used.

Calibration (standard) solutions: The stock solution of phenol was prepared dissolving $250 \mathrm{mg}$ phenol in $500 \mathrm{~mL}$ methanol. The standard solution at $50 \mu \mathrm{g} \mathrm{mL}^{-1}$ was prepared diluting the stock solution with methanol. Then the calibration solutions at $1-15 \mu \mathrm{g} \mathrm{mL}^{-1}$ concentrations were prepared diluting standard solution in methanol.

Recovery studies with standard phenol solutions: XAD-4 was used as clean-up adsorbent. Therefore, first the phenol recovery from XAD-4 adsorbent was investigated using 0.5 or $1.0 \mathrm{~g}$ of the adsorbent. Before use, XAD- 4 was washed with $10 \mathrm{~mL}$ methanol and $10 \mathrm{~mL}$ distilled water of $\mathrm{pH} 2$ successively until no impurities (peaks) were observed on UV spectrum. The preconditioned adsorbent was then put into a pasteur pipette. $1 \mathrm{~mL}$ of standard phenol solution $(\mathrm{pH} \mathrm{2,} \mathrm{no}$ salt, which was chosen by preliminary experiments) was eluted and the adsorbed phenol was recovered using $4 \mathrm{~mL}$ methanol (first $1 \mathrm{~mL}$ of the eluent was discarded).

Recoveries from spiked cigarette tar samples: Since tar has a complex matrix, recoveries from real tar samples, (actually from acetonitrile solution), were investigated. After dissolving a smoked cigarette filter (remaining and filter paper were first removed) in acetonitrile, $30,35,60,70$ or $125 \mu \mathrm{g}$ of phenol (2-mL solutions) was spiked (Table-1). To each, $5 \mathrm{~mL}$ $1 \%$ acetic acid solution was added and then they were thoroughly stirred on a magnetic mixer to let the cellulose acetate precipitate. Then the precipitate was filtered over a blue band filter paper (Advantech, $125 \mathrm{~mm}$, No: 6). $1 \mathrm{~mL}$ of the eluate was brought onto XAD-4 column $(1.0 \mathrm{~g})$ already conditioned. The adsorbed phenol was eluted with $4 \mathrm{~mL}$ methanol (containing $1 \%$ acetic acid). The first coming $1 \mathrm{~mL}$ of the eluate was discarded. Then the next $3 \mathrm{~mL}$ was collected. The eluate was first dried to dryness under nitrogen stream, then, after adding $100 \mu \mathrm{L}$ acetonitrile, $5 \mu \mathrm{L}$ of this solution was injected to high performance liquid chromatography. The chromatogram of filter tar at the concentration level of $70 \mu \mathrm{g}$ cigarette $^{-1}$ obtained after XAD-4 clean-up is shown in Fig. 1.

\begin{tabular}{ccccc} 
TABLE-1 \\
$\begin{array}{c}\text { PER CENT RECOVERIES OF PHENOL FROM SPIKED } \\
\text { CIGARETTE FILTER TAR (1.0 g XAD-4) }\end{array}$ \\
\hline $\begin{array}{c}\text { Spiked amount } \\
\left(\mu \text { c cigarett }^{-1}\right)\end{array}$ & $\left.\begin{array}{c}\text { Found amount } \\
(\mu \mathrm{g} \text { cigarette }\end{array}{ }^{-1}\right)$ & $\% \mathrm{R}$ & $\begin{array}{c}\% \mathrm{RSD}^{\mathrm{a}} \\
(\mathrm{n}=4)\end{array}$ & $\begin{array}{c}\% \mathrm{RSD}^{\mathrm{b}} \\
(\mathrm{n}=3)\end{array}$ \\
\hline 30 & 27.6 & 92 & 12 & 14 \\
35 & 38.5 & 110 & 13 & 16 \\
60 & 72 & 120 & 15 & 19 \\
70 & 84 & 120 & 7 & 10 \\
125 & 104 & 83 & 8 & 12 \\
& Mean & 105 & 11 & 14 \\
\hline
\end{tabular}

${ }^{a}$ Repeatability; ${ }^{b}$ Reproducibility; LOD: $2.17 \mu$ g cigarette ${ }^{-1}$; LOQ: 7.28 $\mu$ g cigarette ${ }^{-1} ; r^{2}=0.9989$.

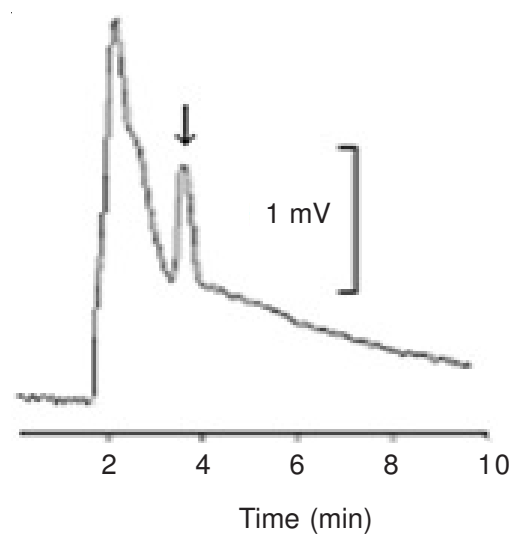

Fig. 1. Chromatogram obtained from SPE-HPLC-UV analysis of filter tar with $70 \mu \mathrm{g}$ cigarette ${ }^{-1}$

Phenol detection in cigarette filter tar: Cigarettes used during our experiments were bought randomly from the market. Since we do not have standard smoking machine, one of our colleagues smoked cigarettes regularly, namely 10 cigarettes per day. Total cigarettes of 100 were used for the recovery experiments. First, the remaining of a butt, together with filter paper, was separated from the filter. Then the filter is dissolved in $2 \mathrm{~mL}$ acetonitrile in an ultrasonic bath. $5 \mathrm{~mL}$ of $1 \%$ acetic acid solution was added to acetonitrile solution drop by drop to precipitate cellulose acetate filter again while being shaken for $15 \mathrm{~min}$. The precipitate was filtered on a blue band filter. The filtrate was added distilled water to make total volume of $7 \mathrm{~mL} .1 \mathrm{~mL}$ of this solution was brought on 
top of a Pasteur pipette containing $1.0 \mathrm{~g} \mathrm{XAD}-4$ adsorbent. After letting passing $1 \mathrm{~mL}$ sample through the column (no pressure was applied) column was first washed with $2 \mathrm{~mL} 1.0$ $\%$ acetic acid solution. Then the retained phenol was eluted using $1+3 \mathrm{~mL}$ methanol at a rate of $0.5 \mathrm{~mL} \mathrm{~min}^{-1}$. The first 1 $\mathrm{mL}$ eluate was discarded since it contained no phenol (proved by UV spectrum). Then $3 \mathrm{~mL}$ eluate was subjected to chromatographic analysis.

\section{RESULTS AND DISCUSSION}

Spectroscopic studies show that the maximum molar absorptivitiy of phenol is obtained at $280 \mathrm{~nm}$ when the solution $\mathrm{pH}$ is 2 . Therefore, throughout the experiments $\mathrm{pH}$ was kept as 2 . Since the recoveries from $1 \mathrm{~g} \mathrm{XAD}-4$ adsorbent were very high (Table-2), thus $1 \mathrm{~g}$ adsorbent was preferred for real sample analysis. Percent recoveries from spiked cigarette filter tar were given in Table-1. Standard deviations also given in Table- 1 were between 7 and $15 \%$. Regression line was $\mathrm{y}=$ $488.9 x+2112.1$ with regression coefficient 0.9989 for concentration ranging from 30 to $125 \mu \mathrm{g}$ cigarette $^{-1}$. LODs and LOQs were calculated using the following equations :

$$
\text { LOD: } y=y_{B}+3 S_{B} ; \text { LOQ: } y=y_{B}+10 S_{B}
$$

where $\mathrm{y}$ is the LOD and LOQ signals (quantities), $\mathrm{y}_{\mathrm{B}}$ is the blank signal; $S_{B}$ is standard deviations of the blank. LODs and LOQs were calculated as $2.17 \mu \mathrm{g}$ cigarette $^{-1}, 7.28 \mu \mathrm{g}$ cigarette $^{-1}$, respectively.

TABLE-2

PER CENT RECOVERIES OF PHENOL FROM XAD-4 SORBENT $(\mathrm{n}=3)$

\begin{tabular}{crrrcc}
\hline XAD-4 $(\mathrm{g})$ & & \%R $^{\mathrm{a}}$ & & Average \%R & \%RSD \\
\hline 0.5 & 70 & 65.2 & 58.6 & 64.6 & 8.9 \\
1.0 & 110 & 102 & 122 & 111.3 & 9.0 \\
\hline
\end{tabular}

${ }^{\mathrm{a}}$ Spiked amount: $5 \mu \mathrm{g} \mathrm{mL} \mathrm{m}^{-1}$

Method validation: For the evaluation of the method, phenol in three brands of cigarette was determined in day and in three successive days using matrix-matched standard addition technique. Under optimized experimental clean-up and enrichment conditions 5 butts from each type was spiked varying amount of standard phenol namely 3-27 $\mu$ g cigarette $^{-1}$. In Table-3, the amount of phenol found in each type of cigarette filter were given. Standard deviations (0.99-2.38) seem a bit varying probably due to smoking regime. However intra-day and inter-day standard deviations (repeatabilities and reproducibilities, do not differentiate much showing the reliability of the proposed method.

\section{Conclusion}

Phenol was determined in cigarette filter tar following the analysis scheme given in Fig. 2. Clean-up with XAD-4 resin to remove the complex matrix of tar without losing phenol was very successful; recovery was as high as $100 \%$. Repeatability and reproducibility (intra-day and inter-day results) were 11 and $14 \%$ respectively proving the reliability of the proposed method. The method is simple and do not need mass spectrometric detector. It is interesting to that the amount of phenol found in different type of cigarette do not deviate much, $9.78 \mathrm{mg}_{\text {butt }}{ }^{-1}$ in average which means $978 \mu \mathrm{g}$ $\mathrm{g}^{-1}$ tar. This shows that the amount of phenol found in tar is almost equal to the amount found in mainstream smoke given in literature from reference 35, the average amount of phenol found in main stream smoke from the low temperature pyrolysis of 5 tobacco (brands) is calculated as $1503 \mu \mathrm{g} \mathrm{g}^{-1} \mathrm{tar}$ (ranging from 1008 to $1963 \mu \mathrm{g} \mathrm{g}^{-1}$ tar). The values are consistent with each other.

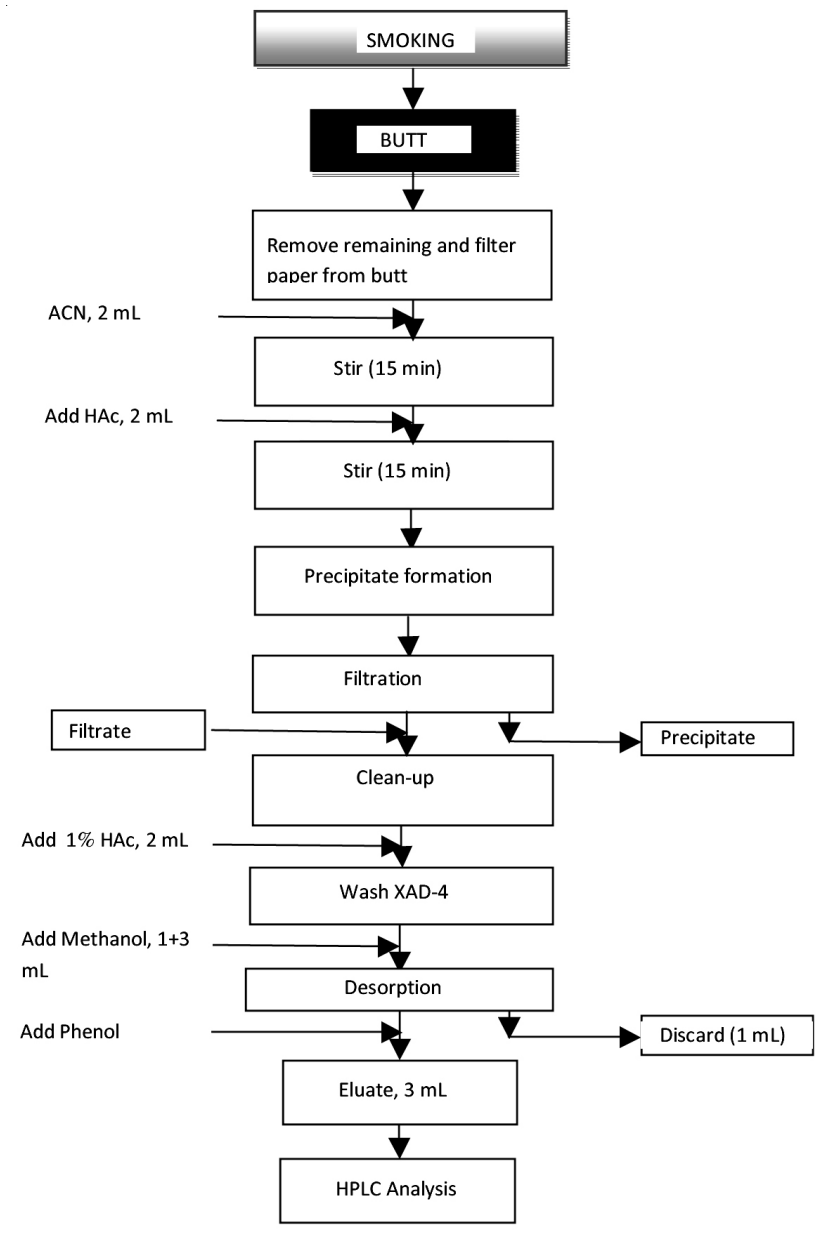

Fig. 2. Analysis scheme of cigarette filter tar

\begin{tabular}{|c|c|c|c|c|c|}
\hline \multicolumn{6}{|c|}{$\begin{array}{c}\text { TABLE-3 } \\
\text { PHENOL FOUND IN VARIOUS BRANDS OF CIGARETTE }\end{array}$} \\
\hline Brand & Tar (mg) & $\mathrm{CO}(\mathrm{mg})$ & $r^{2}$ & $\begin{array}{l}\left.\text { Phenol ( } \mu \text { g cigarette }{ }^{-1}\right) \\
\text { (intra-day) }^{\mathrm{a}}\end{array}$ & $\begin{array}{l}\left.\text { Phenol ( } \mu \text { g cigarette }{ }^{-1}\right) \\
\quad{\text { (inter-day })^{\mathrm{a}}}^{\text {Pan }}\end{array}$ \\
\hline Parliament & 10 & 10 & 0.9972 & $13.02 \pm 1.82$ & $12.70 \pm 2.15$ \\
\hline Samsun $^{\text {b }}$ & 10 & 10 & 0.9951 & $10.23 \pm 0.99$ & $9.52 \pm 1.25$ \\
\hline Tekel $2000^{\mathrm{b}}$ & 10 & 10 & 0.9945 & $6.08 \pm 2.38$ & $7.06 \pm 2.25$ \\
\hline
\end{tabular}

${ }^{\mathrm{a}}$ Values are the mean of four replicates $\pm \mathrm{SD} ;{ }^{\mathrm{b}}$ Turkish tobacco blend. 


\section{ACKNOWLEDGEMENTS}

This study was supported by Kirikkale University Scientific Research Project Coordination Unit.

\section{REFERENCES}

1. M.A. Crespín, M. Gallego and M. Valcarcel, J. Chromatogr. B, 773, 89 (2002).

2. P. Viñas, C. López-Erroz, J.J. Marín-Hernández and M. HernándezCrdoba, J. Chromatogr. A, 871, 85 (2000).

3. T. Andersson, T. Hyötyläinen and M.-L. Riekkola, J. Chromatogr. A, 896, 343 (2000).

4. D. Hoffmann and I. Hoffman, Beitr. Tabakforsch. Int., 18, 49 (1998).

5. C. Amen-Chen, H. Pakdel and C. Roy, Biomass Bioenergy, 13, 25 (1997).

6. W.S. Scholtzhauer and O.T. Chortyk, J. Anal. Appl. Pyrol., 12, 193 (1987).

7. D.L. Davis and M.T. Nielsen, Tobacco: Production, Chemistry and Technology, Blackwell Science, Oxford, p. 281 (1999).

8. J.B. Forehand, G.L. Dooly and S.C. Moldoveanu, J. Chromatogr. A, 898, 111 (2000)

9. P.X. Chen and S.C. Moldoveanu, Beitr. Tabakforsch. Int., 20, 448 (2003).

10. A.J. Dyakonov, R.T. Walker, C.A. Brown, F.R. Perini, D.S. Passer, J. Guan and E.A. Robinson, Beitr. Tabakforsch. Int., 23, 68 (2008).

11. http://www. bat.science.com (2008).

12. F. Aygün, A. Demirci and M. Özcimder, J. Agric. Food Chem., 44 1488 (1996).

13. S.F. Aygün, J. Sep. Sci., 28, 2370 (2005).

14. A. Vermeulen, K. Welvaret and C. Vercammen, J. Chromatogr. A, 1071, 41 (2005).

15. K. Robats, J. Chromatogr. A, 1000, 657 (2003).
16. R. Gatti, M.G. Gioia, A.M. Di Pietra and V. Cavrini, Anal. Chim. Acta, 447, 89 (2001)

17. L. Yang, Z. Wang and L. Xu, J. Chromatogr. A, 1104, 230 (2006).

18. L. Zhang, L. Zhang, W. Zhang and Y. Zhang, Anal. Chim. Acta, 543, 52 (2005).

19. C. Moldoveanu and M. Kiser, J. Chromatogr. A, 1141, 90 (2007).

20. Z. Kovács, Z. Dinya and S. Antus, J. Chromatogr. Sci., 42, 125 (2004).

21. R. Wissiack and E. Rosenberg. J. Chromatogr. A, 963, 149 (2002).

22. S. Vainiotalo, V. Väänänen and R. Vaaranrinta, Environ. Res., 108, 280 (2008)

23. H. Faraji, J. Chromatogr. A, 1087, 283 (2005).

24. G. Pieraccini, S. Furlanento, S. Orlandini, G. Bartolucci, I. Gianinni, S. Punzauti and G. Monetti, J. Chromatogr. A, 1180, 138 (2008).

25. M. Bruijnsvoort, S.K. Sanghi, H. Poppe and W. Th. Kok, J. Chromatogr. A, 757, 203 (1997).

26. I. Rodrigez, M.P. Llompart and R. Cela, J. Chromatogr. A, 885, 291 (2000).

27. M.C. Bruzzoniti, C. Sarzanini and E. Mentasti, J. Chromatogr. A, 902, 289 (2000).

28. G. Karasová and J. Lehotay, J. Liq. Chrom. Rel. Technol., 27, 2837 (2004).

29. Q. Li, X. Wang and D. Yuan, J. Chromatogr. A, 1216, 1305 (2009).

30. Md. Ahmaruzzaman, Adv. Colloid Interf., 143, 48 (2008).

31. H. Bagheri, E. Babanezhad and F. Khalilian, Anal. Chim. Acta, 616, 49 (2008).

32. X. Zeng, Y. Fan, G. Wu, C. Wang and R. Shi, J. Hazard. Mater, 169, 1022 (2009).

33. Z. Czégény, M. Blazs, G. Várhegyi, E. Jakab, C. Liu and L. Nappi, J. Anal. Appl. Pyrol., 85, 47 (2009).

34. R.R. Baker and L.J. Bishop, J. Anal. Appl. Pyrol., 74, 145 (2005).

35. T.E. McGrath, A.P. Brown, N.K. Meruva, and W. Geofrey, J. Anal. Appl. Pyrol., 84, 170 (2009). 